\title{
Biomechanical Behavior of Tooth-Supported Fixed Partial Prostheses Components with Two Different Infrastructures: Metal and Polyether Ether Ketone (Peek)
}

\author{
Santos Heloisa RB, Ávila Gisseli B, Carvalho Geraldo AP, Ramos Elimário V, Franco Aline BG, \\ Franco Amanda G, Dias Sergio C
}

Department of Restorative Dentistry, São Leopoldo Mandic Dental College, Campinas/SP, Brazil

\begin{abstract}
This study uses the finite element method to assess the biomechanical behavior of tooth-supported fixed partial prostheses components manufactured with two different infrastructures: Cr-Co Fit Flex metallic alloy and Polyether Ether Ketone (PEEK) subjected to physiological occlusal loads.

Two models with equal geometry were simulated-Model M1: fixed partial prosthesis with Cr-Co metallic infrastructure and feldspar ceramics coating Noritake Ex-3; Model M2: fixed partial prosthesis with PEEK infrastructure PEEK and indirect resin coating Sinfony. They were subjected to axial and oblique loads. The 3D models were entered in the software CAD Solidworks 2016 for registry and analysis.

Data were analyzed according to the studied factors: dentin behavior, infrastructure, aesthetic coating, detachment pressure between tooth and cement, and tensile stress of cement. Most stress peaks were observed in model M2, but values from the two models were close.

Model M1 showed better results in four of the factors: dentin, infrastructure, detachment pressure between tooth and cement, and cement tensile stress. Model M2 showed better performance in terms of the aesthetic coating. Similar values for both models in most of the simulations suggest a long lifespan of both treatments, although longer for model M1.
\end{abstract}

Key Words: Prostheses, PEEK, Cr-Co Fit Flex metallic alloy

\section{Introduction}

Metal-ceramic prostheses are considered the "gold standard" of oral rehabilitation due to their good mechanical properties along with the clinically accepted quality of their internal and marginal adaptation [1]. They have been used for more than 50 years; however, its dark metallic structure and opaque oxides prevent a natural appearance [2]. To avoid this, studies have been focusing on poly-ether ether ketone (PEEK) as a metal-free alternative for prosthetic rehabilitation with particular advantage for allergic patients or those with bruxism or sensibility to metallic alloys $[3,4]$.

PEEK is a linear semi-crystalline polymer synthesized from aromatic dihalides and bisphenol salt via nucleophilic substitution. It belongs to an important class of highperformance engineering thermoplastics. The presence of aromatic rings confers resistance against mechanical stresses and oxidative and thermal attacks [5]. PEEK presents a high melting point $\left(342.85^{\circ} \mathrm{C}\right)$, high thermal stability, chemical resistance, and radiolucency. At room temperature, it is a rigid polymer and might be semi-crystalline or amorphous according to the processing technique employed [6].

Following confirmation of biocompatibility, [7] PEEK was chosen as an effective biomaterial for implantable medical devices such as orthopedic implants, [8] including spinal and cranial $[9,10]$. In dentistry, PEEK has been investigated for several applications, including dental implants, temporary abutments for implant-supported prostheses, infrastructure for prostheses over the implant, and removable and fixed partial dentures [11-14].

PEEK4 has been proven material with good mechanical properties, mainly for application in areas subjected to load
[15]. It has also shown a low degree of biofilm formation and provides high patient comfort due to its lightweight [16].

Given this context, this study aims to assess the biomechanical behavior of tooth-supported fixed partial prostheses subjected to physiological occlusal loads. To this end, this study uses finite elements to investigate prostheses manufactured with different infrastructures and coatings: chromium-cobalt alloy with feldspar ceramics coating, and PEEK with indirect resin coating. Five factors are monitored: dentin behavior, infrastructure, aesthetic coverage, detachment pressure between tooth and cement, and cement tensile stress.

\section{Materials and Methods}

Virtual jaws were modeled based on computed tomography of a volunteer [17]. The models were edited with elements 35 and 37 and periodontal structures that were the fixed partial prosthesis abutment. Editing was carried on CAD SolidWorks 2017 (Dassault Systems, Solidworks Corps, USA).

Two models were built:

- Model M1, (Control) with metallic infrastructure Cr-Co Fit Flex (Talmax Produtos Odontológicos, Curitiba, Paraná, Brazil) and feldspar ceramic coating Noritake Ex-3 (Noritake Co Limited, Nagoya, Japan)

- Model M2 with PEEK infrastructure Juvora Dental Disc; (JuvoraLtd, Wyre, Lancashire, UK) and indirect resin coating Sinfony (3M Espe, St. Paul, MN, USA)

Prostheses and abutments presented the following characteristics: $1.2 \mathrm{~mm}$ wear on the abutments at the chamfer end and $1.5 \mathrm{~mm}$ at the occlusal; preparation tilt of $6^{\circ}$. Minimum thickness of the infrastructure of $0.3 \mathrm{~mm}$, both 
metallic and PEEK's. Minimum thickness of the aesthetic material of $0.9 \mathrm{~mm}$. Resin cement layer of $62 \mu \mathrm{m}$.

Three occlusal points of contact simulated per tooth with a diameter of $1 \mathrm{~mm}$ each. Bolus with $5 \mathrm{~mm}$ of thickness. Antagonist with healthy enamel.

The models were then exported to the finite element simulation software Ansys Workbench V18.2 (Ansys Inc., Canonsburg, PA, USA), configured with elasticity module and Poisson coefficient according to the literature and with structures considered isotropic, homogeneous and linearly elastic.

Each model was subjected to axial and oblique loads (150 N). Coefficient of friction between bolus and prosthesis of 0.2 . The axial load was applied perpendicularly to the occlusal plane and the oblique load on the vestibulo-lingual orientation at a $45^{\circ}$ angle with the occlusal plane.

The number of nodes/elements is $1,768,172 / 1,044,174$ for the axial loading models and 1,659,348/975,716 for the oblique loading models. All simulations were processed in an Intel I7 6800k, with $112 \mathrm{~Gb}$ of RAM and SO Windows 1064 bits.

\section{Results}

\section{Dentin}

Considering the axial load on dentin, the largest peaks occur at the end region, next to the pontic in model M2 (Figure 1). Model M1 shows more non-occlusal compressive stresses than model M2 (Figure 2).

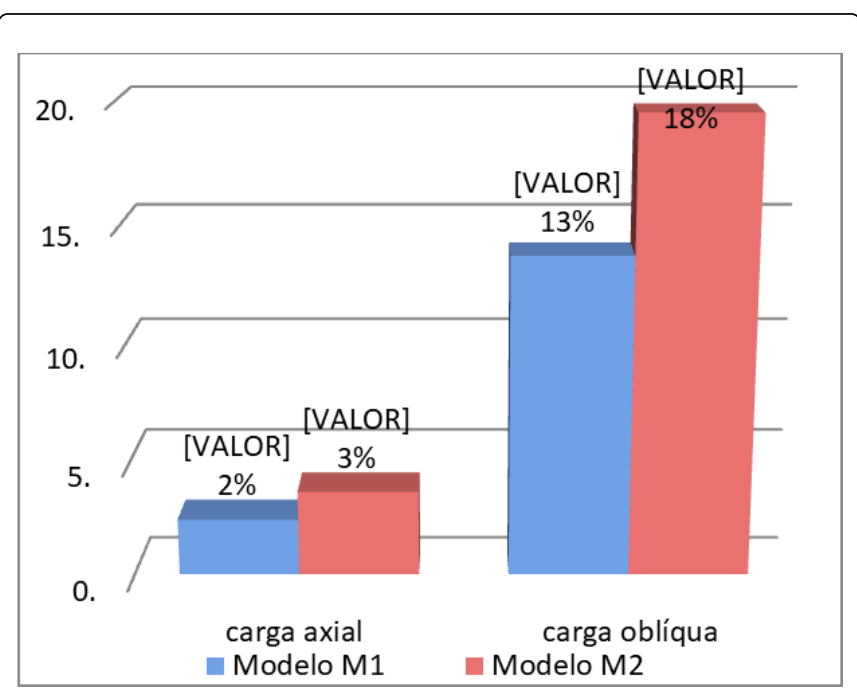

Figure 1. Dentin peaks according to principal maximum stress criterion $(\mathrm{MPa})$.

Results of the oblique load were larger than those of the axial load and the tensile peaks were larger at the premolar teeth of model M2 (Figure 1). The peaks were located at the lingual face of the coronary portion of the dental root, with a larger concentration of compressive stress at the vestibular face and tensile stress at the lingual face (Figure 3).
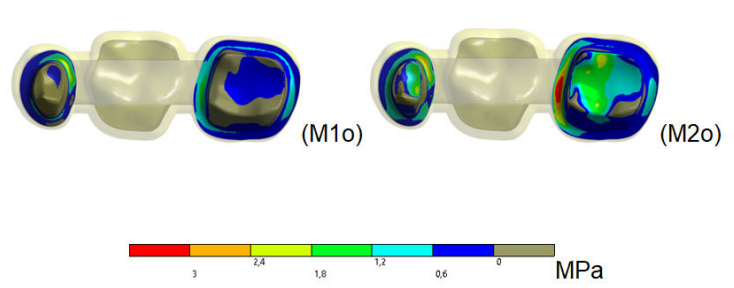

(M1o) and (M2o): occlusal view

Figure 2. Principal maximum stress on dentin under axial load.

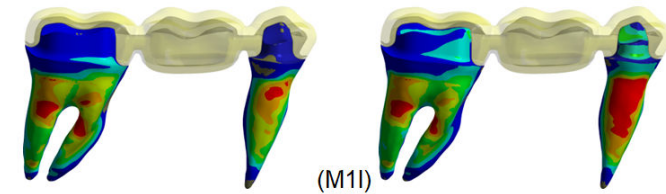

(M2I)

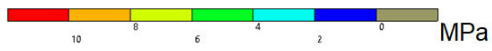

(M1I) and (M2I): lingual view.

Figure 3. Principal maximum stress and probable fracture axis on dentin under oblique load.

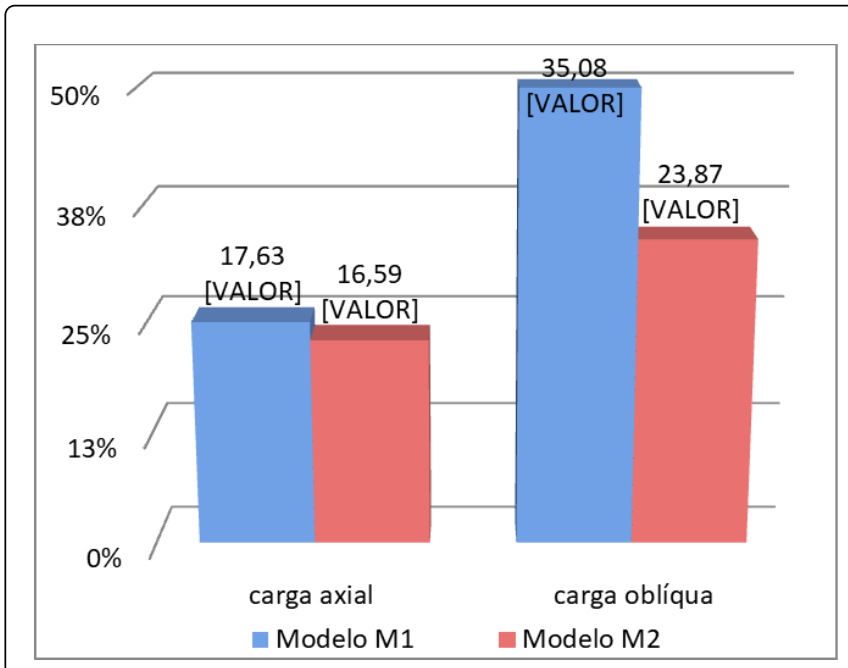

Figure 4. Peaks on aesthetic coating relative to materials resistance, according to principal maximum stress criterion.

\section{Infrastructure}

Tensile strength of chromium-cobalt alloy was considered 710 $\mathrm{MPa}$ [18] and $100 \mathrm{MPa}$ for PEEK [19]. In model M2, the tensile peaks occurred at the cervical proximal portion between pontic and crown under axial load.

Under oblique load, stress was concentrated at the cervical portion of the vestibular face between molars in both models, although larger for model M2. The risk of fracture was larger for model M2; however, the extent of such result suggests a long lifespan of both treatments. 


\section{Aesthetic coating}

Flexural strength of porcelain was considered $69.74 \mathrm{MPa}$ and the tensile strength of resin was considered $70 \mathrm{MPa}$ for the aesthetic coating analysis (Figure 4).

Under an axial load, the largest peaks were observed between molars at the occlusal portion of the vestibular face in model M1 and at the cervical portion of the vestibular face in model M2. The risk of fracture for both models are equivalent (Figure 5).

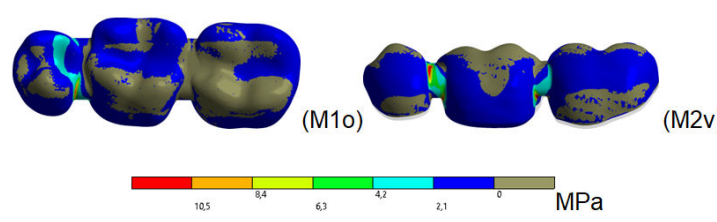

(M1o) occlusal view and (M2v): vestibular view

Figure 5. Principal maximum stress on aesthetic coatings under axial load.

Under oblique load, the largest peaks were observed at the occlusal portion of the vestibular face in both models; however, results show better performance of model M2 (Figure 6).

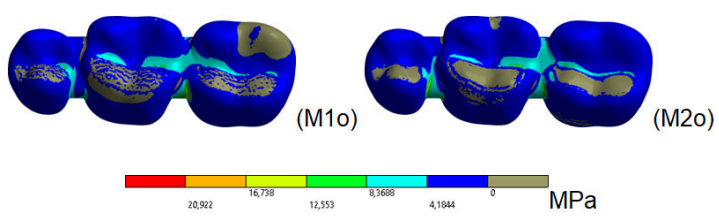

(M10) and (M20): occlusal view

Figure 6. Principal maximum stress on aesthetic coatings under oblique load.

\section{Detachment pressure between tooth and cement}

The study assessed the tensile strength at the interface between tooth and cement that might cause the adhesive failure of cementation. Element 37 of the model M1 was studied as control (Figure 7).

Under an axial load, the risk of adhesive failure was smaller for model M1. It was observed at the mesial wall of the molar tooth in model M1 and at the distal wall of premolar in model M2.

Under oblique load, the largest peak was observed in model M2 concentrated at the distal vestibular face of premolar, which results in the shortest lifespan of the adhesive bond. In model M1, the largest peak was observed at the mesial lingual portion of the molar end.

\section{The tensile stress of cement}

The risk of cohesive failure of cement was assessed through the tensile stress analysis. Element 37 of the model M1 was used as control (Figure 8).

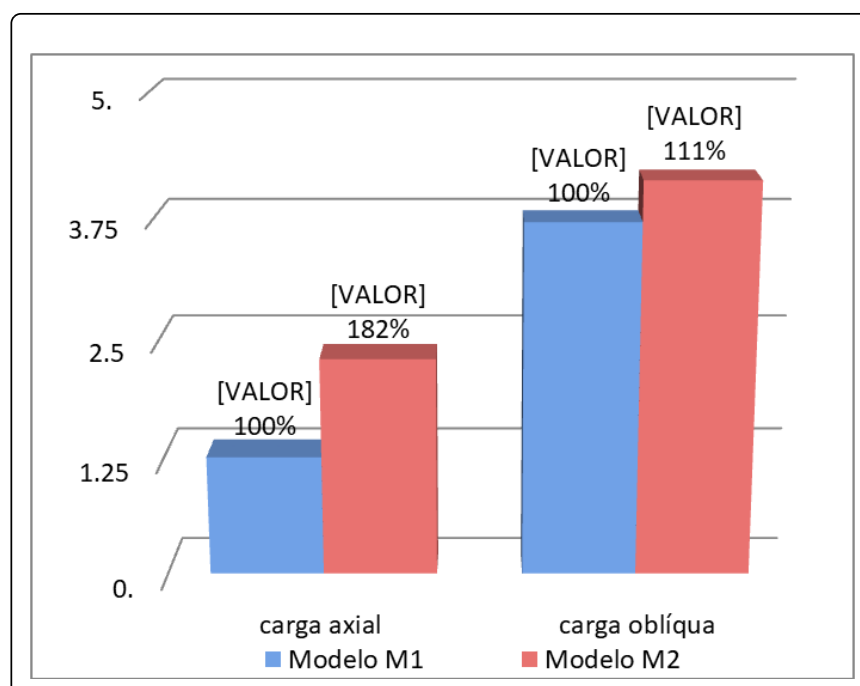

Figure 7. Peaks of traction pressure between cement and dentin (in $M P a$ ).

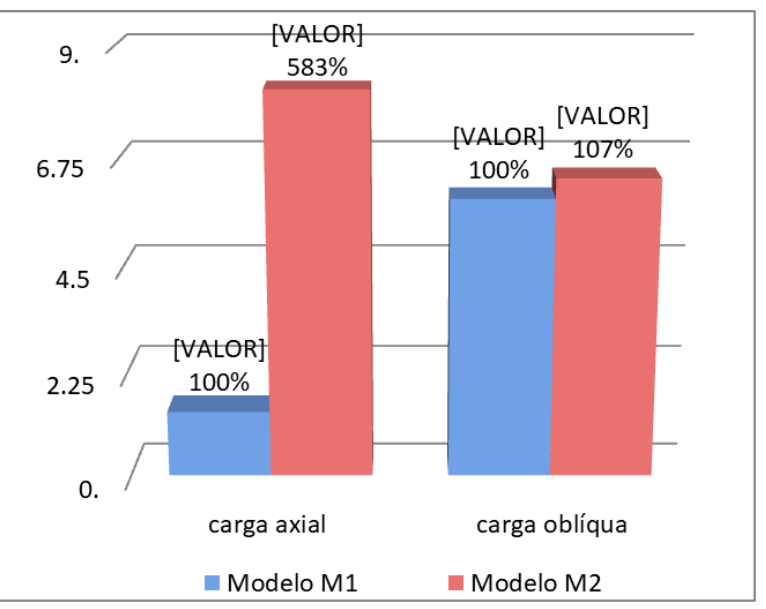

Figure 8. Peaks on cement according to principal maximum stress.

Under an axial load, the model M2 showed a larger risk of cohesive failure, peaking at the distal portion of the premolar end. In model M1, the largest peak was observed at the mesial wall of the molar. This is evidence of the greater performance of model M1 and its resulting larger lifespan.

Under oblique load, the largest peak was observed at the distal vestibular portion of the premolar chamfer in model M2, whilst in model M1 it was observed at the mesial lingual portion of the molar chamfer. Results suggest a slightly inferior cohesive performance of cement of model M2.

\section{Discussion}

Fixed partial dentures must be designed with the ability to resist functional and parafunctional strengths present in the stomatognathic system. The strengths normally absorbed by the absent tooth must be retransmitted through the pontic connector and retainers to the support teeth. If the strength surpassed the physiologic limits of the hard tissue it could cause an initial loss of bone and failure of the prosthesis [20]. Here, a masticatory load of $150 \mathrm{~N}$ was simulated to reproduce 
the average conditions found in vivo, according to Powers et al. [21].

To ensure its effective and safe use in dentistry, a proper assessment of PEEK's properties as infrastructure for fixed partial dentures is necessary, along with the assessment of its influence on dentin behavior, aesthetic coating, detachment, and cement tensile stress.

Dentin tensile strength is $105 \mathrm{Mpa}$ [22]. The largest tensile peaks on dentin were observed in the PEEK-resin model (M2). Under an axial load, it was concentrated at the end portion (next to the pontic), whilst, under oblique load, the peaks were concentrated at the cervical lingual portion of the roots.

The likely fracture axis is the medial and cervical portions of the root, mainly under oblique load, which would lead to the loss of the dental element. This can be explained by the difference of rigidity of materials. Thompson et al. [23], when validating the predictive fracture behavior of the numeric model, showed fractures along the long axis of the tooth - a very bad prognosis. On the other hand, Sobieraj et al. [8] observed that the PEEK samples were in the elastic deformation phase for most of the time.

Stress is mainly concentrated at the connectors in the fixed partial dentures [24,25]. PEEK is a material of good mechanical behavior in the resolution of smaller, extensive, multiple prosthetic cases in the presence of cantilever [1,4]. In the present study, as well as previous ones, the stress was mainly concentrated at the proximal cervical portion, mostly between the molars. However, the risk of fracture was larger for the PEEK-resin model-13\% and 21\% relative to the resistance of materials, under axial and oblique loads, respectively. This small proportion of results suggest a long lifespan of both treatments, although longer in the case of the metal-ceramic model. As observed, oblique strengths produced larger stresses than the axial ones, corroborating other studies [26,27]. This represents an important impact on the fracture of structures.

In addition to its use in infrastructures, PEEK can be used in fixed partial prosthesis with the addition of hydroxyapatite as an option for metal-free restorations with relevant biomechanical behavior. The addition would result in increased tensile strength in comparison with PEEK alone [28]. Another option for metal-free restorations is the fiberreinforced resin fixed partial prosthesis (FRC-FDP) [29,30]. The addition of continuous arrays of reinforcement fibers to the connectors has significantly improved the rigidity of FRCFDP against torsions produced by load and the flexural moment [30]. PEEK reinforcement may be an option to increase its resistance to fracture.

Regarding FRC-FDP performance, fracture and/or delamination of coating composite represent most of the failures $[31,32]$ which shows the relevance of this type of analysis in what concerns fixed prostheses. Here, the risk of fracture of the aesthetic coating was similar for both models (25\% of the risk for the metal-ceramic model, and $23 \%$ for the PEEK-resin model). The difference was proportional to the resistance of materials of $2 \%$, and the largest peaks were observed at the cervical portion between the molars. Thus, results can be regarded as equivalent under axial load. On the other hand, under oblique load, the metal-ceramic model showed worse performance $(50 \%)$, with greater risk of cracking and chipping; however, these percents are considered high, possibly due to the lack of surface treatments in the simulation for both models.

Longevity of fixed partial dentures may be affected by the cementation mode [33], and PEEK prostheses face the same challenges faced by other metal-free prostheses [34,35] Regarding detachment pressure between cement and tooth under axial load, the largest stress peaks were observed in the PEEK-resin model $(2.31 \mathrm{MPa})$ and was concentrated at the distal portion of the premolar. Under oblique load, the stress increased to $4.14 \mathrm{MPa}$ and compression was observed at the lingual, vestibular portion of the chamfer and occlusal table. The risk of adhesive failure was larger in the PEEK-resin model due to the smaller rigidity of the infrastructure, which favors a larger concentration of stress on the premolar and smaller on the molar. This will eventually result in a shorter lifespan of the adhesive bonding in comparison with the metal-ceramic model.

Regarding cement tensile stress, the risk of cohesive failure was larger for the PEEK-resin model. A difference of $11 \%$ was observed relative to the metal-ceramic model and the tensile peaks of cement were observed at the distal portion of the premolar chamfer, both under axial and oblique load. The smaller rigidity of the infrastructure favors a non-uniform distribution of stresses that, associated with the phenomenon of compressive deformation, produces a more extensive effect of peripheral traction.

Some authors suggest the physical and chemical pretreatment of the surface to increase the shear bonding strength of PEEK prosthesis and circumvent adhesive and mixed failures [36,37] However, the present simulation lacked the surface treatment prior to cementation for both models.

The elucidation of PEEK's inherent features and its biomechanical behavior with further studies using different methodologies can lead to its clinical application considering its numerous advantages, including aesthetics and biocompatibility relative to metal.

\section{Conclusion}

Among the five factors studied here, the metal infrastructure with feldspar coating (M1) showed superiority in four of them: dentin, infrastructure, detachment pressure between cement and tooth, and cement tensile stress. The PEEK infrastructure and indirect resin coating (M2) showed better performance only in terms of aesthetics. However, both models showed similar results in most simulations, suggesting a long lifespan for both treatments, although longer for M1.

\section{References}

1. Zarone F, Russo S, Sorrentino R. From porcelain-fused-tometal to zirconia: clinical and experimental considerations. Dental Materials. 2011; 27: 83-96.

2. Pjetursson BE, Sailer I, Zwahlen M, Hämmerle CH. A systematic review of the survival and complication rates of allceramic and metal-ceramic reconstructions after an observation 
period of at least 3 years. Part I: single crowns. Clinical Oral Implants Research. 2007; 18: 73-85.

3. Parmigiani JM. Peek, alternativa a aleaciones metálicas en la boca. Odontología Sin Metal. Maxillaris. 2015: 157-167.

4. Schwitalla AD, Spintig T, Kallage I, Muller WD. Flexural behavior of PEEK materials for dental application. Dental Materials. 2015; 31: 1377-1384.

5. Rocha RF, Anami LC, Campos TM, Melo RM, Souza RO, et al. Bonding of the polymer polyetheretherketone (peek) to human dentin: Effect of surface treatments. Brazilian Dental Journal. 2016; 27: 693-699.

6. Dandy LO, Oliveux G, Wood J, Jenkins MJ, Leeke GA. Accelerated degradation of Polyetheretherketone (PEEK) composite materials for recycling applications. Polymer Degradation and Stability. 2015; 112: 52-62.

7. Rivard $\mathrm{CH}$, Rhalmi S, Coillard C. In vivo biocompatibility testing of peek polymer for a spinal implant system: a study in rabbits. Journal of Biomedical Materials Research. 2002; 62: 488-498.

8. Sobieraj M, Murphy J, Brinkman J, Kurtz SM, Rimnac. Notched fatigue behavior of PEEK. Biomaterials. 2010; 31: 9156-9162.

9. Kurtz SM, Devine JN. PEEK biomaterials in trauma, orthopedic, and spinal implants. Biomaterials. 2007; 28: 4845-4869.

10. El Halabi F, Rodriguez JF, Rebolledo L, Hurtos E, Doblaré M. Mechanical characterization and numerical simulation of polyether-ether-ketone (PEEK) cranial implants. Journal of the Mechanical Behavior of Biomedical Materials. 2011; 4: 1819-1832.

11. Najeeb S, Zafar MS, Khurshid Z, Siddiqui F. Applications of polyetheretherketone (PEEK) in oral implantology and prosthodontics. Journal of Prosthodontic Research. 2016; 60: 12-19.

12. Carvalho GA, Franco AB, Kreve S, Ramos EV, Dias SC, et al. Polyether ether ketone in protocol bars: Mechanical behavior of three designs. Journal of International Oral Health. 2017; 9: 202-209.

13. Jaros OA, De Carvalho GA, Franco AB, Kreve S, Lopes PA, et al. Biomechanical behavior of an implant system using polyether ether ketone bar: Finite element analysis. Journal of International Society of Preventive and Community Dentistry. 2018; 8: 446-450.

14. Aquino MMO, Kreve S, Carvalho GAP, Ramos EV, Franco $\mathrm{ABG}$, et al. Cantilever protocol bars in acrylated polyether ether ketone (peek): a mechanical compression assay. Oral Health and Dental Management. 2018; 17: 1-4.

15. Stawarczyk B, Beuer F, Wimmer T, Jahn D, Sener B, et al. Polyetheretherketone-A suitable material for fixed dental prostheses? Journal of Biomedical Materials Research Part B. 2013; 101B: 1209-1216.

16. Sinha N, Gupta N, Reddy KM, Shastry YM. Versatility of PEEK as a fixed partial denture framework. Journal of Indian Prosthodontic Society. 2017; 17: 80-83.

17. Vasco MAA, Castellano MD, López JB, de las Casas EB. Utilização de tomografias computadorizadas de baixa resolução para construção de modelos geométricos detalhados de mandíbulas com e sem dentes. Revista Internacional de Métodos Numéricos para Cálculo y Diseño en Ingeniería. 2016; 31.

18. Morris HF. Properties of cobalt-chromium metal ceramic alloys after heat treatment. Journal of Prosthetic Dentistry. 1990; 63: 426-433.

19. Invibio. PEEK-OPTIMA natural typical material properties. west Conshohocken, USA: Invibio biomaterial solutions. 2013.

20. Oruc S, Eraslan O, Tukay HA, Atay A. Stress analysis of effects of nonrigid connectors on fixed partial dentures with pier abutments. Journal of Prosthetic Dentistry . 2008; 99: 185-192.

21. Powers JM, Sakaguchi RL. Craig's restorative dental materials. 12th ed. St. Louis: Mosby. 2006: 35-36.
22. Sano H, Ciucchi B, Matthews WG, Pashley DH. Tensile properties of mineralized and demineralized human and bovine dentin. Journal of Dental Research. 1994; 73: 1205-1211.

23. Thompson MC, Field CJ, Swain MV. The all-ceramic, inlay supported fixed partial denture. Part 3. Experimental approach for validating the finite element analysis. Australian Dental Journal. 2012; 57: 23-30.

24. Shinya A, Matsuda T, Nakasone Y, Shinya A. Hybrid resin fixed partial dentures reinforced with glass fiber-optimum posterior fiber frame design with finite element analysis. Journal of Dental Materials. 2004; 23: 186-192.

25. Ohyama T, Nakamura T, Nakamura T, Imanishi A. Stress analysis of fiber-reinforced metal-free polymer bridges using twodimensional finite element method. Journal of Esthetic Dentistry. 2003; 15: 184-186.

26. Kou W, Qiao J, Chen L, Ding Y, Sjogren G. Numerical simulation of the fracture process in ceramic FPD frameworks caused by oblique loading. Journal of the Mechanical Behavior of Biomedical Materials. 2015; 50: 206-214.

27. Modi R, Kohli S, Rajeshwari K, Bhatia S. A three-dimension finite element analysis to evaluate the stress distribution in tooth supported 5-unit intermediate abutment prosthesis with rigid and nonrigid connector. European Journal of Dentistry. 2015; 9: 255-261.

28. Wang L, Song S, Zhang Z, Tian S, Ma R. Characterization of polyether ether ketone-hydroxyapatite nanocomposite materials. Materials Science and Engineering. 2011; 528: 3689-3696.

29. Ahmed KE, Li KY, Murray CA. The longevity of fiberreinforced composite fixed partial dentures (FRC FPD)-Systematic review. Journal of Dentistry. 2017; 61: 1-11.

30. Aida N, Shinya A, Yokoyama D, Lassila LV, Gomi H, et al. Three-dimensional finite element analysis of posterior fiberreinforced composite fixed partial denture Part 2: influence of fiber reinforcement on mesial and distal connectors. Dental Materials Journal. 2011; 30: 29-37.

31. Göhring TN, Roos M. Inlay-fixed partial dentures adhesively retained and reinforced by glass fibers: clinical and scanning electron microscopy analysis after five years. European Journal of Oral Sciences. 2005; 113: 60-69.

32. Van Heumen CC, Kreulen CM, Creugers NH. Clinical studies of fiber-reinforced resin-bonded fixed partial dentures: A systematic review. European Journal of Oral Sciences. 2009; 117: $1-6$.

33. Edelhoff D, Özcan M. To what extent does the longevity of fixed dental prostheses depend on the function of the cement? working group 4 materials: cementation. Clinical Oral Implants Research. 2007; 18: 193-204.

34. Zhou L, Qian Y, Zhu Y, Liu H, Gan K, et al. The effect of different surface treatments on the bond strength of PEEK composite materials. Dental Materials. 2014; 30: e209-215.

35. Sproesser O, Schmidlin PR, Uhrenbacher J, Roos M, Gernet $\mathrm{W}$, et al. Effect of sulfuric acid etching of polyetheretherketone on the shear bond strength to resin cements. The Journal of Adhesive Dentistry. 2014; 16: 465-472.

36. Rosentritt M, Preis V, Behr M, Sereno N, Kolbeck C. Shear bond strength between veneering composite and PEEK after different surface modifications. Clinical Oral Investigations. 2015; 19: 739-744.

37. Schwitalla AD, Botel F, Zimmermann T, Sutel M, Muller WD. The impact of argon/oxygen low-pressure plasma on shear bond strength between a veneering composite and different PEEK materials. Dental Materials. 2017; 33: 990-994. 